\title{
Strategies to Attract Customers From the Aspect of the Taste of Bread, the Supply Model and the Colors of the Product
}

\author{
Liushun Zhao \\ The Barstow School Ningbo Campus, Ningbo, Zhejiang, 325000, China \\ Corresponding author's e-mail: Vivian.wang@cas-harbour.org
}

\begin{abstract}
As the bakery and pastry industry in the mainland China has been developing rapidly in the 21th century, in this paper, how to attract as many customers as possible are discussed from the aspect of the taste and type of the bread, the supply model and the colors. The author did a survey to collect data on what kind of bread they like. Moreover, literature analysis is used to investigate the suitable kind of bread, the best supply model and the colors. According to the results, people aged 10-19 mostly like to eat sweet bread; people aged 20-29 years old prefer to eat sweet or spicy bread. This bread brand aims at young people, so most of the bread in the bakery will be sweet. Besides, European style soft bag will be chosen as the web celebrity product or the representative product, because this type of bread conforms with the taste of Chinese people and the flavor is especially suitable for the young people. Moreover, just like the sub-brands of HEYTEA, bakeries will also create subbrands, using the own unique style and flavor of each sub-brand to meet the needs of more people. What is more, the brand will choose to make the bread on-site in the store and sell it on the spot to guarantee the freshness of the taste and make customers feel at ease about the quality of bread. As to the colors of products, red and yellow will be chosen in priority for these colors can stimulate people's appetite. In addition, the color blue or purple should be avoided, since they make the food look unpalatable.
\end{abstract}

Keywords : Bread, taste, supply, appetite, color

\section{INTRODUCTION}

The freshly made bread is the most tempting. The hot aerosol rises from circle to circle, sending the light milk and wheat aromas to people. People cannot dislike it. So many people never get out once they enter the bread pit. Some discerning entrepreneurs have also targeted the bakery industry and want to open a bakery. Bakery and bakery products were introduced into mainland China from Hong Kong and Taiwan in the 1980s. After a period of adaptation, China's bakery and pastry industry has shown a rapid development trend since the beginning of the 21 st century. Nowadays, bread and pastries are entering a peak period, people's living standards have improved, and the frequency of buying bread and cakes has increased. Many people have chosen and delicious bread and delicious pastries for their daily afternoon tea and breakfast supper, and the sales of bread are increasing year by year. For example, Shima Baking, a baking brand that inherits French romance. The baked products are unique, with a natural flavor, simple and delicious fragrance, which makes people put it down. France is a romantic and passionate nation. Delicate and delicious French cake desserts represent sweetness and love, and also show the optimism of the French[2]. Besides, in order to keep up with the pace of the times, people's pace of life has gradually become faster and faster. It is undeniable that many young office workers now have to save time for the work by cutting down the time for eating as much as possible. However, fast food like instant noodles, snacks, burgers are not healthy and they all have a bad effect on health. So using bread as a staple food is a great option. Hence, the author's focus is on the fragmented time of eating. In addition, to successfully run a bread brand, the most important thing is to know how to attract more customers and find ways to cater to the tastes of more people. Whereas, not only the taste of bread is important, but also the decoration of the store, the services people enjoy and the various publicity are also very important. So the author adopted some methods to understand the preferences of people in today's society, so as to better create a successful brand.

The author will further improve his topic through some other aspects related to taste, so that readers can get more information in author's paper and understand his thoughts and opinions better. In the stage of preparing the paper, author made a survey report to help him better understand the tastes of people in today's society, and analyzed the results after collecting data. First of all, the author will start from the selection of the taste of bread through a questionnaire. In the following thesis, HEYTEA will be taken as an example to elaborate how to cater to the market by opening sub-brands. Then, the most suitable supply model will be chosen from four supply models of different products. The author will consider from the perspective of consumers and try to make the supply chain of his own brand as open and transparent as possible, so that consumers 
will be more confident about the raw materials and quality of products. Fourthly, the author will briefly introduce the star product of this bread brand, which is the representative work of this brand -- European light bread, and explain the reason why this kind of bread will be chosen as the main product. Finally, the author will mention the influence of food color on people's appetite, and how to attract more consumers like brand products from this aspect.

\section{ANALYSIS ON THE FAVORABLE TASTE}

\subsection{Design of the questionnaire}

At first, the author made a questionnaire. 36 people from different ages, 18 men and 18 women participated in this survey. They were asked which taste was their favorite bread tastes: sweet, salty, light or spicy. Besides, the testee was divided into six age groups with three men and three women in each group.

\subsection{The result of the questionnaire}

To begin with, children aged 10-19 mostly like to eat sweet bread; people 20-29 years old prefer to eat sweet or spicy bread; people 30-39 years old prefer light or spicy bread; people 40-49 more willing to choose light or salty bread; people 50-59 years old prefer light bread; people 60-69 years old also prefer light bread. In addition, through investigation, author can find that the taste of men is heavier than taste of women. More men will like to eat salty or spicy bread, while women will prefer light bread. Author thinks the taste and taste one likes also permeates different attitudes towards life. Just like steaks, young people prefer muscle and bone steaks, tough taste, broken, pulled, confrontation; and older people prefer the soft rotten meat that is slowly simmered. Therefore, in order to cater to the tastes of more people, author will choose to create his own sub-brand or divide his own bread into different series, the target customers of different series are also different. The sensitivity of different genders to food is also different, so I also analyzed and distinguished the tastes of men and women[4].

\section{TYPE OF BRAND}

Every brand has one or several representative products of its own brand. Representative products of a brand are very necessary and important. Such representative products determine the first impression of customers on this brand. Therefore, the main product of this bread brand author created will be European soft bread. Nowadays, the development situation of soft European bread is getting better and better. The improvement of people's health awareness and the almost harsh pursuit of food taste have made this natural and healthy delicious food a new favorite of young people and a baking industry trend.

\subsection{Basic Introduction of European Soft Bread}

European soft bread is a kind of European bread. The characteristics of European bread are high fiber, low sugar, low oil, low fat. Therefore, it is healthy. But unlike the formal European bread, which have a harder texture and a little bit of taste, the soft European bread are more chewy, softer, and more in line with Asian tastes. Therefore, for those who pursue health and food, breakfast or afternoon tea is a great choice for a soft European bread. Compared with traditional conditioning breads, the price of soft European bread is relatively higher. It is reported that older bakery brands such as Santa Ana, Luyeju, Bakery, Queen Bakery, etc. have introduced soft European bread. Mostly 15-20 yuan per piece, while the traditional bread price is about 8-15 yuan per piece. In addition, from last year to this year, there have also been many bakeries that focus on soft European bread, such as the wheat brand warehouse of the bakery brand of the Bakery Group, which is also the main European-style bread. Thus, consumers' enthusiasm for European soft bread is evident.

\subsection{Reasons for choosing this kind of bread}

First of all, China is the second largest economy in the world, and people's modern living standards have also rapidly improved. The Chinese have long shifted from "full eating" to "good eating"; from "willing" to "exquisite", advocating high-quality taste life, especially more and more obvious among the new generation of young people. A brand new lifestyle that pursues personalized tastes has been formed, especially the rise of the younger generation of bread consuming groups, which requires high-level and innovative bread products. Soft European bread came into being, and it is not surprising that they have become popular. Moving on, The European soft bread is more suitable for the Chinese stomach. Chinese people do not like European-style bread. Even Shanghai, a place that can accept foreign cultures, still cannot accept hard Europeanstyle bread. Japanese bread is high in sugar, high in oil, and high in calories. It is no longer suitable for the healthy demands of modern people. Large and hard European bread is healthy, but it does not meet the taste habits of the Chinese. A soft European bread that is more suitable for the Chinese population's sense of preference and health came into being. The soft European bread is actually a balance between hard European bread and Japanese soft bread. With the appearance of the European bun, the heart of the soft bun is more suitable for the Chinese stomach. Thirdly, Health and fashion are becoming more and more popular. European soft bread absorbs the healthy genes of traditional European bread and is more suitable for the general public's eating habits. A soft European bread mixed with high-fiber, 
multigrain, nuts and other materials is a combination of traditional European bread and Japanese-style soft bread. Less oil, less sugar and no eggs, crispy outside and soft inside, more chewy than soft bread, softer than hard buns, low in calories and full, it can be said that it is a new trend of bread health[1].

\section{SUB-BRAND}

According to the above research, people of different ages have different tastes and preferences, so it is difficult for a brand to attract all types of customers. In order to attract as many customers as possible, some sub-brands are needed. Therefore, the author uses HEYHEA as an example to further explain the marketing model of sub-brands. HEYTEA is a kind of milk-tea brand and also offers bread. Because both HEYTEA and the bread brand the author wants to create are desserts, which are targeted at similar customer groups and are more popular among young people. HEYTEA opened many different kinds of sub-brands and each of them offers different products. The decoration styles, raw materials, tastes, groups and prices of these subbrands are completely different. HEYTEA develops several sub-brands in the "beverage shop" market where it plays. HEYTEA Bakery offering freshly baked bread and also the drinks, HEYTEA LAB holding exhibition and providing laboratory environment, HEYTEA GO supporting ordering from WeChat applet, HEYTEA PINK filled with pink decorations, HEYTEA BLACK furnished with dark elements and HEYTEA DP In the HEYTEA DP plan, HEYTEA will collaborate with designers from different fields to bring bolder space design. Even in the real world, people can occasionally daydream are the sub-brands underneath the master brand. Although the sub-brands are designed in different styles, them are all named with HEYTEA and characterized by it. Consumers can easily distinguish them from the numerous beverage shops in the market and make their choice based on their loyalty to HEYTEA.

\section{SELECTION OF SUPPLY MODEL}

Regarding the supply of bread, here are some examples and models: Model 1: Represented by Christine, the model of front store and back factory. Features: small regional chain stores and individual stores are dominant, and overall sales are in a passive mode. Mode 2: Central factory and regional chain model represented by $85^{\circ} \mathrm{C}$. Features: based on the scatter model, integrate regional internal resources to form a regional strong brand and provide chain support through a unified front-end system. Mode 3: Central factory represented by LIND and on-site baking mode. Features: follow the unified factory distribution, but only deliver raw materials or semi-finished products. The central kitchen of the store is now baked and sold. Provide diversified operation of terminals, and copy and expand to the whole country. Mode 4: Central factory and on-site baking and light catering space mode. Features: adhering to the central factory and on-site baking, and combining light catering mode, forming a combined operation between catering and bread products.

Bread is a very perishable product, so the mode of supply is also an important factor in terms of speed when the quality of the product is guaranteed. Therefore, I think model 1 is the best choice, because making bread directly in the store is not only fast, but also can ensure the fresh taste of bread, and also let customers see the production process of each step of bread.

\section{SELETION OF COLORS}

One's taste is difficult to change, but the appetite of customers can be stimulated through product packaging, store decoration, assured raw materials and quality service, thus making them have the will to buy products. Usually blue, purple black and black foods should be avoided, because people habitually think that these foods will deteriorate or be harmful to human health[3]. Except for lingonberries, gooseberries and eggplant, there are not many foods of this color. However, although some foods are naturally not these colors, they were later dyed to these colors, so they do not have these effects. The famous candy company was forced to withdraw the bright blue candy it had launched after receiving many complaints. Blue food continues to win the title of the most appetizing food. One study did the following experiment: Ask people (including their competitors) their favorite foods, then dye them blue, and then let them eat them. The results showed that the blue food was immediately found to be the most unappetizing, even though the food tasted normal. Red food (and red itself) will stimulate appetite and give people a feeling of vitality. If people have poor appetite, then add some red things to people's food[3]. Yellow is also a color that stimulates appetite because it is often associated with happiness[3]. Have people noticed that some restaurants will install yellow painted windows or put yellow flowers on the tables? This warm color will make people feel more popular and hungry. Visual assistance is also important. If people change the color of the beverages people drink frequently, most people will not be able to recognize their own beverages. The University of Washington conducts a lot of research on how taste is affected by color. In a research project, the subjects tasted the drink and were able to see the true color of the drink. In this case, they can always correctly recognize the taste of the drink. However, when they cannot see the color of the drink, they will recognize it wrong. For example, when the subject was not allowed to see the color, only $70 \%$ tasted it as a grape drink, and $15 \%$ thought it was citric acid[3]. Only $30 \%$ of people who tasted the cherry drink thought it was a cherry[3]. Most people think that cherry drink is citric acid. Because McDonald's uses colors intelligently, McDonald's red and yellow packaging is rated as the best food packaging. For one thing, these two colors can increase the sense of hunger. For another, they are also very friendly and unforgettable for the customers[3]. 


\section{CONCLUSION}

For people nowadays, bread is no longer just a food to fill the stomach, it is more a way of life[5], so the trend of the entire baking industry is from ordinary bakery to fashion bakery, light luxury is the mainstream, it can be seen that in addition to the more fashionable decoration of the current bakery, the product line is also more diversified and more high-end oriented.

Just like HEYTEA, whose target group is the young generation, so most of the bread in the bakery will be sweet. Considering that there are also other different flavors available for the general public, bakeries will also create sub-brands with different representative products to cater to more people's tastes. For the supply model, the brand will choose to make the bread on-site in the store and sell it on the spot to guarantee the freshness of the taste and make customers feel at ease about the quality of bread. What is more, according to the analysis results, red and yellow, which can stimulate people's appetite, will be chosen to decorate the stores and be printed on the package of the products.

To successfully open a bread brand requires much more than what are discussed in this paper. For example, the detailed analysis of this industry, the competitors, and the political environment are also significant. Moreover, the analysis of the customers' needs is still insufficient. In this paper, only the flavor of the bread is investigated through the questionnaire with a very small number of testee. Hence, a more comprehensive survey with more questions will be conducted in the future.

\section{ACKNOWLEDGMENT}

I am grateful to those who helped me in this paper. Because I had little experience in writing papers before, my adviser and professor patiently solved and answered my questions. In addition, I also want to feel that those who actively cooperate with me in completing the survey report will be of great help to my paper and help me to better understand the taste of the current public. All in all, only those who help me in the paper can let me finish the paper finally. Thanks!

\section{REFERENCES}

[1] Gaoduan Naicha Yinpin Peifang. Why is European soft bread becoming more and more popular. May 19, 2017, accessed on June 16, 2020, retrieved from: https://www.sohu.com/a/141783688_823169

[2] Sanrenxing. Why is the baking industry growing. November 23, 2019, accessed on June 16, 2020, retrieved from: https://zhuanlan.zhihu.com/p/93321091
[3] Baidu library. What color makes you want to eat. 2019, accessed on June 16, 2020, retrieved from

https://wenku.baidu.com/view/8d2d29c1326c1eb91a37f11 1f18583d049640fb3.html

[4] T. R. Alley and W. J. Burroughs. Do men have stronger preferences for hot, unusual, and unfamiliar foods? The Journal of general psychology 118.3 (1991): 201-214.

[5] K. Dewettinck, et al. Nutritional value of bread: Influence of processing, food interaction and consumer perception. Journal of Cereal Science 48.2 (2008): 243-257. 